\title{
A case of typical pulmonary carcinoid tumor treated with bronchoscopic therapy followed by lobectomy
}

This article was published in the following Dove Press journal:

Journal of Multidisciplinary Healthcare

20 February 2012

Number of times this article has been viewed

\author{
Konstantinos Porpodis' \\ Michael Karanikas ${ }^{2}$ \\ Paul Zarogoulidis' \\ Theodoros Kontakiotis' \\ Alexandros Mitrakas ${ }^{2}$ \\ Agisilaos Esebidis ${ }^{2}$ \\ Maria Konoglou ${ }^{3}$ \\ Kalliopi Domvri' \\ Alkis lordanidis ${ }^{4}$ \\ Nikolaos Katsikogiannis ${ }^{5}$ \\ Nikolaos Courcoutsakis ${ }^{4}$ \\ Konstantinos Zarogoulidis' \\ 'Pulmonary Department, \\ "G Papanikolaou" General Hospital, \\ Aristotle University of Thessaloniki, \\ Greece; ${ }^{2}$ Ist University Surgery \\ Department, University General \\ Hospital of Alexandroupolis, \\ Democritus University of Thrace, \\ Greece; ${ }^{3}$ Ist Pulmonary Department, \\ "G Papanikolaou" General Hospital, \\ Thessaloniki, Greece; ${ }^{4}$ Radiology \\ Department, University General \\ Hospital of Alexandroupolis, \\ Democritus University of Thrace, \\ Greece; ${ }^{5}$ Surgery Department (NHS), \\ University General Hospital of \\ Alexandroupolis, Greece
}

Correspondence: Paul Zarogoulidis

Pulmonary Department,

"G Papanikolaou" General Hospital,

Aristotle University of Thessaloniki,

Exohi Thessalonikis 570I0,

Thessaloniki, Greece

Tel +30 697727 I974

$\mathrm{Fax}+302310992433$

Email pzarog@hotmail.com

\begin{abstract}
Carcinoid bronchopulmonary tumors represent approximately $25 \%$ of all carcinoid tumors and $1 \%-2 \%$ of all lung neoplasms. The most common symptoms are: persistent cough, asthma-like wheezing, chest pain, dyspnea, hemoptysis and obstructive pneumonitis. We present a case of a young adult diagnosed with a typical carcinoid tumor. The diagnosis was established on the basis of imaging examination and bronchoscopic biopsy. The patient was treated with bronchoscopic electrocautery therapy to relieve the obstructed airway, followed by surgical lobectomy in order to entirely remove the exophytic damage. This approach was not only a palliative management to bronchial obstruction but also avoided pneumonectomy. Recent studies support the use of such interventional resection methods, as they may result in a more conservative surgical resection.
\end{abstract}

Keywords: carcinoid tumor, typical lung carcinoid, therapeutic bronchoscopy, surgical resection

\section{Introduction}

Carcinoid tumors develop from stem cells of the bronchial epithelium known as Kulchitsky cells, which have neuroendocrine activity. These neuroendocrine cells can develop tumors in many different organs with most common being the lungs, the appendix, the small intestine (duodenum), the rectum and the pancreas. ${ }^{1}$ The most recent classification system from the World Health Organisation categorized neuroendocrine pulmonary tumors in four types: typical carcinoid; atypical carcinoid (ATC); large cell neuroendocrine carcinoma; and small cell lung cancer. ${ }^{2}$

Carcinoid bronchopulmonary tumors represent approximately $25 \%$ of all carcinoid tumors and $1 \%-2 \%$ of all lung neoplasms. ${ }^{3}$ Approximately $70 \%$ of these tumors are located centrally in the large bronchial tubes leading to the lung, while $10 \%-20 \%$, known as peripheral carcinoids, develop in the pulmonary periphery. ${ }^{4}$

Typical carcinoid pulmonary tumors manifest nine to ten times more often than ATC tumors. They are characterized by slow development and rare metastasis to other organs. Typical carcinoid tumors are seen in younger patients more often than ATCs and appear to be the most frequent pulmonary neoplasms during childhood and puberty. 5,6 ATC lung tumors have a more aggressive histologic appearance and a greater tendency to metastasize than typical carcinoid lung tumors. These tumors are more frequent in males, and the average age of onset is 46 years. ${ }^{7}$

Unlike most lung cancers, the development of carcinoid pulmonary tumors is not related to smoking or other environmental causes (eg, tobacco smoke, air pollution, or asbestos). The detection of carcinoid tumorlets in lung biopsies led to speculation that 
carcinoid tumors may grow from these cells. ${ }^{1}$ However, further research needs to be conducted as this association has not been yet determined.

\section{Case report}

A 26-year-old female presented with wheezing episodes, cough and mild dyspnea. After a chest x-ray revealed normal findings and spirometry showed mild restriction (Table 1), she was commenced on bronchodilators and inhaled corticosteroids. Two years later, the symptoms were not entirely relieved and she had developed hemoptysis of approximately $10 \mathrm{~mL} / 24$ hours. Therefore, she was referred to the pulmonary department for further examinations.

During clinical examination the patient had reduced respiratory whistling and mild wheezing in the upper left pulmonary field. The results of the exams revealed normal blood tests, a mild restrictive spirometry (Table 1), a negative Mantoux and a left perihilar shadow in the chest radiograph (Figure $1 \mathrm{~A}$ and $\mathrm{B}$ ). A chest high resolution computed tomography was performed showing a nodule in the left primary bronchus causing its partial obstruction (Figure 2). The suspicion of malignancy was established and the patient underwent a bronchoscopy (Olympus BF-P240; $6 \mathrm{~mm}$ insertion tube, biopsy channel $2.6 \mathrm{~mm}, 55 \mathrm{~cm}$ working length, [Olympus Corp, Tokyo, Japan]). The findings showed exophytic damage with increased vascularization in the left primary bronchus $5 \mathrm{~cm}$ from the carina. This picture was compatible with a carcinoid tumor. The tumor was biopsied and the specimen was sent for histological examination. The biopsy demonstrated a typical carcinoid and the patient underwent pelvic and cerebral computed tomography, which both showed normal findings.

In an effort to avoid pneumonectomy, and to produce rapid palliation of hemoptysis and immediate tumor debulking, bronchoscopic electrocautery was selected as the most appropriate procedure.

A rigid bronchoscopy was inserted into the trachea under general anesthesia using a $7.5 \mathrm{~mm}$ Storz rigid

Table I Spirometries performed pre- (first visit, upon diagnosis) and post-operatively (after treatment)

\begin{tabular}{llll}
\hline & First visit & $\begin{array}{l}\text { Upon } \\
\text { diagnosis }\end{array}$ & $\begin{array}{l}\text { After } \\
\text { treatment }\end{array}$ \\
\hline FVC & $2.25 / 61 \%$ & $2.04 / 55.6 \%$ & $3.50 / 95.3 \%$ \\
$\mathrm{FEV}_{1}(\mathrm{~L}), \%$ Pred & $2.10 / 66.7 \%$ & $1.93 / 61.3 \%$ & $3.20 / 101.6 \%$ \\
$\mathrm{FEV}_{\text {I } / \mathrm{FVC}}$ & $0.93 / 0.87$ & $0.95 / 0.87$ & $0.91 / 105.5$ \\
(Measured/predicted) & & & \\
\hline A & & &
\end{tabular}

Abbreviations: $\mathrm{FVC}$, forced vital capacity; $\mathrm{FEV}_{1}$, forced expiratory volume in I second; \%Pred, percentage of predicted normal value. bronchoscope (Karl Storz Gmbh and Co, Tuttlingen, Germany). Electrocautery (power setting of 40 Watts, blend mode, normal coagulation, electrosurgical monopolar unit PSD-20, with foot switch, flexible monopolar electrocautery blunt probe Olympus CD-6C-1, loop snare, [Olympus, Tokyo, Japan]) was performed on the exophytic tumor tissue followed by mechanical removal. This intervention fully re-opened the obstructed left main bronchus and the upper subsegment of the left upper lobe. The remaining tissue in the obstructed lower subsegment of the left upper lobe was treated by surgical resection, performing a lobectomy to remove the tissue entirely. During this procedure, three lymph nodes (subsegmental and segmental) were also removed. The final report stated that there was no expanding malignancy affecting the pleural cavity or the lymph nodes.

The patient was not given chemotherapy but was followed up with regular medical monitoring combined with imaging studies (ie, chest x-ray, chest computed tomography). Five years after surgical treatment, the patient was asymptomatic with normal chest radiographs and normal spirometry (Table 1; Figure 1C).

\section{Discussion}

About $25 \%$ of patients with carcinoid lung tumors are asymptomatic. ${ }^{8}$ The severity and variety of symptoms depend on the size of the carcinoid pulmonary tumor and the production of hormones. In symptomatic patients with central carcinoids, the most common symptoms are: persistent cough, asthma-like wheezing, chest pain, dyspnea, hemoptysis and obstructive pneumonitis. ${ }^{9}$ A number of studies have reported that a mistaken diagnosis of asthma is frequent in these cases, delaying early diagnosis. Peripheral carcinoid tumors rarely manifest any symptoms.

Occasionally, carcinoid pulmonary tumors may initiate an excessive hormonal secretion causing various neuroendocrine syndromes such as carcinoid syndrome and Cushing syndrome. ${ }^{9,10}$ The most common symptoms of carcinoid syndrome are: facial flushing, sweating, diarrhea, rapid cardiac beats and wheezing. Even more rarely, patients with Cushing syndrome caused by the abnormal overproduction of cortisol can develop muscle weakness, obesity in the upper body, high blood pressure, high blood sugar and increased body and facial hair.

Almost $90 \%$ of typical carcinoid tumors are diagnosed at an early stage while more than $50 \%$ of ATC tumors are diagnosed at stage II or III. ${ }^{11}$ The diagnosis of carcinoid pulmonary tumor is established on the basis of the patient's symptoms combined with imaging examination such as chest 

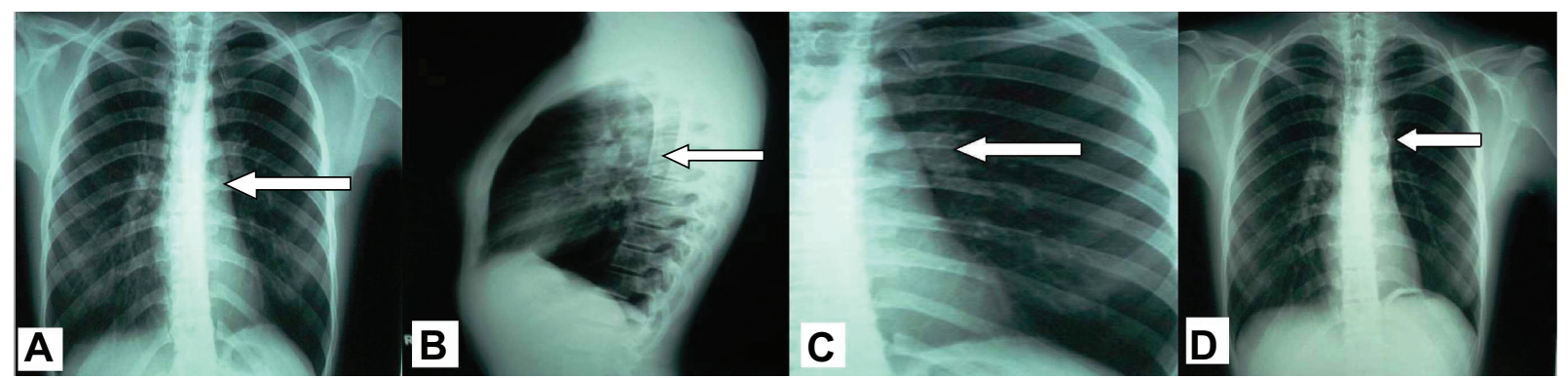

Figure I Chest radiographs: (A and B) before treatment with arrow showing a left perihilar shadow, (C) After treatment (surgery) arrow indicates (D) staples on 5-year follow up.

radiography, computed tomography and magnetic resonance imaging. ${ }^{12}$ To verify the histologic type of the pulmonary tumor detected, there are several biopsy options including bronchoscopic biopsy, needle biopsies and surgical biopsies (eg, thoracotomy). ${ }^{13}$ However, it has been reported that bronchoscopic biopsy has a risk of hemorrhage, especially in cases of partial or total removal of vascular tumors. ${ }^{14}$

The primary and most effective treatment for all pulmonary carcinoid tumors is surgical resection as long as no contraindications to surgery exist (eg, widespread metastatic disease). ${ }^{15}$ Chemotherapy and radiotherapy have no therapeutic contribution and there is no verified optimal therapy for unresectable carcinoid lung tumors. ${ }^{16}$

There are a variety of resection techniques that treat lung carcinoids effectively. ${ }^{13}$ Presently, the most commonly utilized resection procedure is lobectomy. For smaller tumors located in the periphery or within a pulmonary segment, surgeons may perform segmental resection or wedge resection. Sleeve resection is usually performed for central lesions. In rare cases, a bilobectomy or pneumonectomy may be required due to the size or the location of the tumor. Postoperatively, the most common complications are excessive bleeding, atelectasis and prolonged air leak. ${ }^{13}$

Interventional therapeutic bronchoscopies such as laser bronchoscopy, electrocautery therapy, cryotherapy, endobronchial brachytherapy, photodynamic therapy and airway stents may also be performed in certain cases. ${ }^{17,18}$ Nd-YAG lasers and electrocautery, together with mechanical tumor removal, are more appropriate for rapid palliation and immediate tumor debulking. ${ }^{19}$ In particular, electrocautery therapy, as applied in our case, can achieve immediate relief of the symptoms resulting from obstructed airways in $55 \%-75 \%$ of patients. Its advantages over laser treatment include cost effectiveness, higher availability,
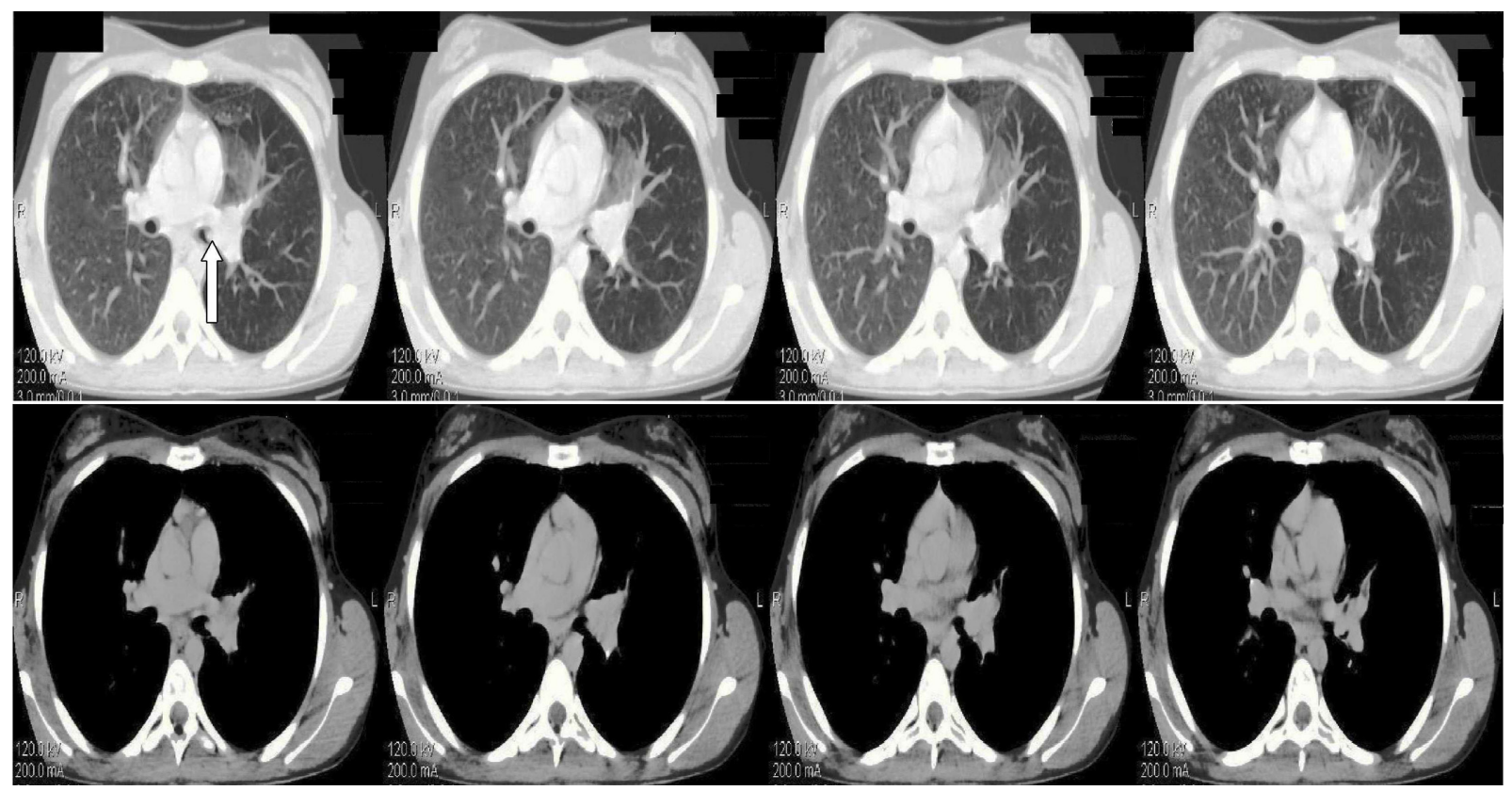

Figure 2 Chest HRCT showing nodule development in the left primary bronchus causing its partial obstruction (arrow) before treatment. Abbreviation: HRCT, high resolution computed tomography. 
and faster removal of tumors and components resistant to laser coagulation. ${ }^{18}$ Moreover, in a study evaluating the degree of damage and bronchial wall healing after photodynamic, Nd-YAG laser, and electrocautery therapy, electrocautery produced the least amount of airway scarring and subepithelial fibrosis. ${ }^{19}$ In another study, the amount of mucosal damage visualized after electrocautery was correlated with histologic tissue damage. The investigators concluded that this is a potential advantage of electrocautery compared to other therapies, where the real histologic damage may be more severe than what is visualized after the therapy. ${ }^{20}$ Side effects of electrocautery therapy include burn, haemorrhage, and inadvertent electrical shock to the endoscopist or the patient, but there are no reports of treatment-related deaths or respiratory failure episodes. ${ }^{18,21}$

These bronchoscopic techniques are usually used for palliative management of bronchial obstruction, for mass reduction prior to surgery, or for patients unsuitable for formal surgery. ${ }^{18}$ A number of studies of endobronchial resection have confirmed that bronchoscopic techniques are successful modalities of treatment. ${ }^{22}$ Several therapeutic modalities used in conjunction may be essential to achieve the best management of the disease, rather than a single invasive approach. ${ }^{23}$ In a recent review, even though $50 \%$ of patients underwent a lung resection after a single bronchoscopic resection, the authors reported that the inability to remove the remaining tumor was entirely due to the inaccessibility of the tumor. ${ }^{24-26}$ Some experts believe that tumor reduction by this method may result in a more conservative surgical resection. ${ }^{15}$ Our study confirms these findings as the use of bronchoscopic electrocautery followed by surgical lobectomy not only removed the tumor entirely but also avoided pneumonectomy.

Among pulmonary malignancies, carcinoid tumors have the highest prognostic rates. Typical carcinoid tumors have better prognoses than the atypical forms. The 5-year survival rate reaches $92 \%-100 \%$ for typical lung carcinoids and only $61 \%-88 \%$ for ATCs. ${ }^{27}$ Previous studies have shown that lymph node involvement as well as the presence of tumorlets, have significant negative effects on prognoses. ${ }^{28}$

Early suspicion, combined with imaging examination and biopsy, is the key to diagnosis. Improved surgical techniques allow smaller incisions resulting in shorter hospitalization and less postoperative pain. ${ }^{19}$ Many studies suggest that the use of endobronchial management techniques not only improve clinical symptoms and quality of life, but also increase overall survival. ${ }^{21,23}$ Therefore, performing less invasive procedures should be considered throughout the management of lung cancer patients, provided no poor prognostic factors exist. ${ }^{29}$ Series utilizing this mode of therapy must be reported in order to determine long-term outcomes.

A carcinoid tumor may be considered a challenging disease due to its infrequency. It is very important that scientists continue to investigate and publish results from such cases so that new information about the etiology and treatment of the disease can be made available.

\section{Disclosures}

The authors declare no conflicts of interest in this work. Written informed consent for publication of this case report and all accompanying images was obtained from the patient upon discharge.

\section{References}

1. Vuitch F, Sekido Y, Fong K, Mackay B, Minna JD, Gazdar AF. Neuroendocrine tumors of the lung: pathology and molecular biology. Chest Surg Clin North Am. 1997;7(1):21-47.

2. World Health Organization Classification of Tumors. Pathology and Genetics. Tumors of the Lung, Pleura and Heart. Lyon, France: IARC Press; 2004.

3. Asamura H, Kameya T, Matsuno Y, et al. Neuroendocrine neoplasms of the lung: a prognostic spectrum. J Clin Oncol. 2006;24(1):70-76.

4. Rosado de Christenson ML, Abbott GF, Kirejczyk WM, Galvin JR, Travis WD. Thoracic carcinoids: radiologic-pathologic correlation. Radiographics. 1999;19(3):707-736.

5. Grote TH, Macon WR, Davis B, Greco FA, Johnson DH. Atypical carcinoid of the lung: a distinct clinicopathologic entity. Chest. 1988;93(2):370-375.

6. Wang LT, Wilkins EW Jr, Bode HH. Bronchial carcinoid tumors in pediatric patients. Chest. 1993;103(5):1426-1428.

7. Valli M, Fabris GA, Dewar A, Hornall D, Sheppard MN. Atypical carcinoid tumour of the lung: a study of 33 cases with prognostic features. Histopathology. 1994;24(4):363-369.

8. Ducrocq X, Thomas P, Massard G, et al. Operative risk and prognostic factors of typical bronchial carcinoid tumors. Ann Thorac Surg. 1998;65(5):1410-1414.

9. McCaughan BC, Martini N, Bains MS. Bronchial carcinoids. Review of 124 cases. J Thorac Cardiovasc Surg. 1985;89(1):8-17.

10. Ilias I, Torpy DJ, Pacak K, Mullen N, Wesley RA, Nieman LK. Cushing's syndrome due to ectopic corticotropin secretion: twenty years' experience at the National Institutes of Health. J Clin Endocrinol Metab. 2005;90(8):4955-4962.

11. Travis WD, Rush W, Flieder DB, et al. Survival analysis of 200 pulmonary neuroendocrine tumors with clarification of criteria for atypical carcinoid and its separation from typical carcinoid. Am J Surg Pathol. 1998;22(8):934-944.

12. Soubani AO. The evaluation and management of the solitary pulmonary nodule. Postgrad Med J. 2008;84(995):459-466.

13. Pagana KD, Pagana TJ. Mosby's Manual of Diagnostic and Laboratory Tests, 4th ed. St Louis: Mosby; 2010.

14. Medford ARL. Electrocautery, bronchoscopic biopsy and hemorrhage. Ann Thorac Med. 2011;6(1):48-49.

15. Daddi N, Ferolla P, Urbani M, et al. Surgical treatment of neuroendocrine tumors of the lung. Eur J Cardiothorac Surg. 2004;26(4):813-817.

16. Thomas CF Jr, Tazelaar HD, Jett JR. Typical and atypical pulmonary carcinoids: outcome in patients presenting with regional lymph node involvement. Chest. 2001;119(4):1143-1150. 
17. Machuca TN, Cardoso PF, Camargo SM, et al. Surgical treatment of bronchial carcinoid tumors: a single-center experience. Lung Cancer. 2010;70(2):158-162.

18. Prakash UB. Advances in bronchoscopic procedures. Chest. 1999; 116(5):1403-1408.

19. van Boxem AJ, Westerga J, Venmans BJ, Postmus PE, Sutedja G. Photodynamic therapy, Nd-YAG laser and electrocautery for treating early-stage intraluminal cancer: which to choose? Lung Cancer. Jan 2001;31(1):31-36.

20. van Boxem TJ, Westerga J, Venmans BJ, Postmus PE, Sutedja TG. Tissue effects of bronchoscopic electrocautery: bronchoscopic appearance and histologic changes of bronchial wall after electrocautery. Chest. 2000;117(3):887-891.

21. Bolliger CT, Sutedja TG, Strausz J, Freitag L. Therapeutic bronchoscopy with immediate effect: laser, electrocautery, argon plasma coagulation and stents. Eur Respir J. 2006;27(6):1258-1271.

22. Sutedja TG, Schreurs AJ, Vanderschueren RG, Kwa B, vd Werf TS, Postmus PE. Bronchoscopic therapy in patients with intraluminal typical bronchial carcinoid. Chest. 1995;107(2):556-558.

23. Ernst A, Feller-Kopman D, Becker HD, Mehta AC. Central airway obstruction. Am J Respir Crit Care Med. 2004;169(12):1278-1297.
24. Luckraz H, Amer K, Thomas L, Gibbs A, Butchart EG. Long-term outcome of bronchoscopically resected endobronchial typical carcinoid tumors. J Thorac Cardiovasc Surg. 2006;132(1):113-115.

25. Deygas N, Froudarakis M, Ozenne G, Vergnon JM. Cryotherapy in early superficial bronchogenic carcinoma. Chest. 2001;120(1): 26-31.

26. Froudarakis M, Fournel P, Burgard G, et al. Bronchial carcinoids. A review of 22 cases. Oncology. 1996;53(2):153-158.

27. Garcia-Yuste M, Matilla JM, Cueto A, Paniagua JM, et al. Spanish Multi-centric Study of Neuroendocrine Tumours of the Lung for the Spanish Society of Pneumonology and Thoracic Surgery (EMETNE-SEPAR). Typical and atypical carcinoid tumours: analysis of the experience of the Spanish Multi-centric Study of Neuroendocrine Tumours of the Lung. Eur J Cardiothorac Surg. 2007;31(2): 192-197.

28. Chughtai TS, Morin JE, Sheiner NM, Wilson JA, Mulder DS. Bronchial carcinoid-twenty years' experience defines a selective surgical approach. Surgery. 1997;122(4):801-808.

29. Herth FJF. Endobronchial management of central cancers. In: Spiro SG, Huber RM, Janes SM, editors. Thoracic Malignancies. European Respiratory Society Monograph. 2009;44:336-348.
Journal of Multidisciplinary Healthcare

\section{Publish your work in this journal}

The Journal of Multidisciplinary Healthcare is an international, peerreviewed open-access journal that aims to represent and publish research in healthcare areas delivered by practitioners of different disciplines. This includes studies and reviews conducted by multidisciplinary teams as well as research which evaluates the results or conduct of such teams or

\section{Dovepress}

healthcare processes in general. The journal covers a wide range of areas and welcomes submission from practitioners at all levels, from all over the world. The manuscript management system is completely online and includes a very quick and fair peer-review system. Visit http://www.dovepress.com/testimonials.php to read real quotes from published authors.

Submit your manuscript here: http://www.dovepress.com/journal-of-multidisciplinary-healthcare-journal 